
\title{
R Reserach S Suare \\ The Epidemiological and Spatio-temporal Characteristics of 2019 Novel Coronavirus Diseases (COVID-19) in Libya
}

Mohamed A Daw ( $\sim$ mohamedadaw@gmail.com )

Faculty of Medicine, University of Tripoli https://orcid.org/0000-0003-1312-5956

Abdallah H El-Bouzedi

University of Tripoli

Mohamed 0 Ahmed

University of Tripoli

Research article

Keywords: Libya, COVID-19, Epidemiology, Spatiotemporal analysis, Dynamics , Geography

Posted Date: August 31st, 2020

DOI: https://doi.org/10.21203/rs.3.rs-57985/v1

License: (c) (i) This work is licensed under a Creative Commons Attribution 4.0 International License.

Read Full License 


\section{Abstract}

Background: COVID-19 is a global pandemic that affected all aspects of life. Studies on understanding the geographical and epidemiological characteristics become particularly important in controlling the spread of the pandemic. Such studies are lacking in Northern African countries particularly in Libya, which considered being, the second largest country in Africa with the longest coast facing Europe. The objectives of this study are to; determine the epidemiological parameters and spatiotemporal patterns of COVID-19 in this large country and outline the needed strategies to contain the spread and the consequences of the pandemic.

Methods: This comprehensive study included all the confirmed cases of COVID-19 since its emergence in Libya, from early April 2020 until August $31^{\text {th }}$. The epidemiological characteristics of COVID-19 were analyzed and the spatial dynamic trends were explored. A region -based counts of weekly reported cases were used to characterize and quantify the spatial dynamics of COVID-19.

Results: A total 3695 of confirmed cases of OVID-19 were collected, 2515(68.1\%) were males and $1180(31.9 \%)$ female with a male-to-female(M:F) ratio 2.1:1. Aged between $2-78$ years old. Older age patients infected with COVID-19 are at higher severity and mortality. A broad geographic variability and Spatiotemporal spread variation of the COVID-19 pandemic in Libya was observed. Indicating a higher significant increase of COVID-19 from the middle of July particularly in the West and Southern regions although it was consistently observed in Meddle and Southern regions.

Conclusion: Evaluating the epidemiological data and the spatiotemporal dynamic trends of COVID-19 at early stages are particularly important in understanding the pandemic spread. These parameters are essential in designing effective prevention and control programs aimed at reducing the impact of COVID19 pandemic particularly in countries with limited resources.

\section{Background}

The ongoing coronavirus disease (COVID-19) pandemic has reached each country in the world and no one can be considered safe. The pandemic affects all aspects of life, socially, economically, politically and even morally. Since its emergence, countries and health authorities responded comprehensively but differently[1]. However, the impact may vary both between and within countries, partly because of the degree to which control strategies are adopted and executed. Countries like, Sweden, and Germany responded early and successfully. Though others such as Italy, Spain and France, the action was different and thus it resulted in a high number of deaths [2-4]. The impact was even worse in developing countries such as Iran and Brazil as the early action was improper and influenced by virtual local understanding $[5,6]$. Hence then, the epidemiology and the impact of COVID-19 varies greatly from one country to another and thus understanding these epidemiological parameters became particularly important to each country. 
In Africa, the Incidence of COVID-19 varies considerably between countries possibly reflecting variations in volumes of air travel and differences in coverage of SARS-CoV-2 testing [7]. The preparation of tackling COVID-19 is becoming increasingly difficult in Northern and sub-Saharan countries, where the effects of the internal armed conflicts and the emergence of other viral epidemic on the economy and health structures are still being felt $[8,9]$. However, only a few African states have been successful in implementing detection, prevention, and control measures. Yet the COVID-19 pandemic poses a challenge not only for fragile African countries but also for those with well-functioning health systems. Until now, studies evaluating the epidemiological and spatial spread of the COVID-19 pandemic in Africa are limited. However, understanding the spread of the COVID-19 outbreak is critical to predicting local outbreaks and developing public health policies during the early stages of COVID-19[10,11].

Libya, the second largest country in Africa with the longest coast in the Mediterranean facing Europe has been involved in an armed conflict since 2011. The country is considered vulnerable to the spread of infectious diseases such as COVID-19. As armed conflicts and internal instability challenge disease control and have a very deleterious effect on provision of health services [12,13]. Due to low levels of international commerce and travel in the country, the seeding of COVID-19 was delayed compared to other Northern African countries [14]. The first few cases of COVID-10 embarked in Libya were arrived from Italy and Egypt as early March this year. Now, that COVID-19 has taken a strong hold in the country, displaced people and immigrants can help spread from one city to another[15,16]. Accordingly, it is expected that COVID-19 is likely spreading rapidly and undetected in the Libyan community. Hence then understanding the epidemiological manifestations and local variation in the dynamics of the pandemic is a crucial step in developing more effective strategies for mitigating risk of infection in vulnerable communities. Unfortunately, to date, there is not a global and standard response to the pandemia and each country is facing the crisis based on their own possibilities, expertise and hypotheses [17].

Different studies have been made to analyze the epidemiological manifestations and geographic mapping of COVID-19[10,18]. Such information are particularly important not only in framing and controlling COVID-19 but also for planning, how to combat the consequences and aftermaths of this vital pandemic. However, there is lack of information regarding the epidemiology and clinical features of COVID-19 patients in North Africa, particularly Libya. Therefore, the objectives of this study were to evaluate the epidemiological and spatiotemporal distribution of COVID-19 in Libya and highlights the needed strategies and how appropriately allocate the healthcare resources to combat the spread of the pandemic.

\section{Methods}

\section{Patients' information and data collection}

The demographic data and epidemiological information, clinical symptoms and outcomes from all reported cases of COVID-19 between March 24,2020 till July 31,2020 allocated by National Centre for Disease Prevention (NCDC)were collected. All investigation, contact tracing, and quarantine were 
conducted by the NCDC at regional or district level. The data were recruited from all registered patients and extracted from the hospital records and checked by clinical epidemiologist. Furthermore, the dailyupdated numbers were cumulated from all confirmed COVID-19 cases across all the Libyan regions.

\section{Case definitions}

The definitions of the confirmed cases of COVID-19 were based on our previous publication [14,19]. Among all confirmed cases, the degree of clinical severity was categorized as following criteria : Mild cases were defined are those with only mild symptoms, without evidence of pneumonia and even they don't require oxygen therapy. Moderate cases are those with fever, respiratory tract symptoms, and imaging shows pneumonia. Severe cases are those who have of the following signs: (a) respiratory distress, respiratory rate 30 beats / $\mathrm{min}$; (b) in the resting state, finger oxygen saturation 93\%) arterial blood oxygen partial pressure (PaO2/oxygen concentration (FiO2) $300 \mathrm{mmHg}(1 \mathrm{mmHg}=0.133 \mathrm{kPa})$. Critical cases were defined as those who are exhibiting , respiratory failure, requires mechanical ventilation and septic shock occurs. ICU admission is required with multiple organ dysfunction/failure.

\section{Laboratory testing of COVID-19}

Laboratory confirmation of COVID-19 is being done by the National Center for Disease Control. Nasopharyngeal and oropharyngeal swab samples are collected following standard safety procedures. RNA is extracted using QIAamp ${ }^{\mathrm{TM}}$ viral RNA mini kit from Qiagen ${ }^{\mathrm{TM}}$ according to the manufacturer's instructions, as previously published [20]. Analysis is done by the real-time reverse transcriptasepolymerase chain reaction (RT-PCR) for all suspected cases following the protocol established by the WHO. Biosafety cabinets are used and the work is done according to laboratory biosafety guidelines [21].

\section{Statistical analysis}

A descriptive statistical analysis was performed to analyze the epidemiological characteristics of confirmed cases of COVID-19 using computer software version 11.0 (StataCorp. 2013. Stata Statistical Software: Release 13. College Station, TX: StataCorp LP). Logistic regression was conducted to identify the factors associated with COVID-19 infection. Data were expressed as means \pm standard deviation (SD), and as number and percentage with $95 \%$ confidence interval (Cl), as appropriate. Spatiotemporal analysis and geographic mapping of COVID-19 cases was carried out using GraphPad Software as previously described[22-24]

\section{Results}

The study population consisted of all confirmed cases of COVID-19 reported in Libya by July 31 (12.00 AM) 2020. A total of 3695 were reported, the epidemiological and clinical characteristics of the these 
cases were illustrated in Table 1. Of 3695 cases , 2515(68.1\%) were males and 1180(31.9\%) female with a male-to-female(M:F) ratio 2.1:1. Aged between $2-78$ years old. The number of a live cases was reported to be $3621(98 \%)$ and only 74 ( $2 \%$ ) cases we dead. The case fatality rate was higher among males 53 (71.6\%), though it was only $21(28.4 \%)$ among females. Of the deceased cases $39(52.7 \%) \geq 55$ age group particularly over 66 years, although only 5 (6.6\%)cases below 40 years and $21(28.4 \%)$ cases aged between $41-55$ years. Epidemiological investigations indicated that of these cases, 782(21.2\%)were Imported, though 2913(78.8) cases acquired locally ( $p=<0.001)$. Those imported cases were mainly from Egypt 257(32.9\%),Turkey 219(28\%), Tunisia 209 (\%26.7) and Saudi 96 (12.3\%) cases . The largest number of cases was reported in Western Region with a total of 1755(47.5\%) cases with 23(31.1\%) deaths, followed by Southern Region 1133(30.7\%)cases with 31(41.9) deaths. Although, Eastern Region reported $738(20 \%)$ cases and $9(12.2 \%)$ deaths and the Meddle region has $429(11.1 \%)$ cases and $11(14.9 \%)$ deaths . Of all confirmed case-patients, $2330(36.1 \%)$ were mild, $1108(30 \%)$ moderate, $128(3.5 \%)$ ), sever and 91 129(3.5\%) were critical. The highest mortality rate was reported among Critical and sever cases which was found to be $38(51.4 \%)$ and $26(35.1 \%)$ respectively ( $P>0.001)$ while it was only moderate $7(9.5$ $\%)$ and mild 3(4.1\%) and cases. 
Table 1

Epidemiologic Characteristics of 3695 confirmed case-patients with COVID-19 Infection in Libya.

\begin{tabular}{|c|c|c|c|c|}
\hline Demographic Characteristics & Alive & Death & Total & $P$ value \\
\hline Total No (\%) & $(\mathrm{No}=3621)$ & $(\mathrm{No}=74)$ & $(\mathrm{No}=3695)$ & \\
\hline \multicolumn{5}{|l|}{ Gender } \\
\hline Male & $2462(68)$ & $53(71.6)$ & $2515(68.1)$ & $<0.001$ \\
\hline Female & 1159(32) & $21(28.4)$ & $1180(31.9)$ & 0.01 \\
\hline \multicolumn{5}{|l|}{ Age group } \\
\hline$\leq 15$ & $86(2.38)$ & $0(0)$ & $86(2.3)$ & 0.01 \\
\hline $16-20$ & $142(4)$ & $0(0)$ & 142(3.8) & 0.01 \\
\hline $21-25$ & $161(4.5)$ & $1(1.4)$ & $162(4.5)$ & 0.02 \\
\hline $26-30$ & $241(7.5)$ & $0(0)$ & $241(6.5)$ & 0.01 \\
\hline $31-35$ & $271(7.5)$ & $0(0)$ & $271(7.3)$ & 0.01 \\
\hline $36-40$ & $307(9)$ & $3(4.1)$ & $310(8.4)$ & 0.01 \\
\hline $41-45$ & $327(9)$ & $5(6.8)$ & $332(9)$ & 0.01 \\
\hline $46-50$ & $350(9.5)$ & $7(9.5)$ & $367(10)$ & 0.01 \\
\hline $51-55$ & $379(10.5)$ & $9(12.2)$ & $388(10.5)$ & 0.01 \\
\hline $56-60$ & $398(11)$ & $13(17.6)$ & $409(11.1)$ & $<0.001$ \\
\hline $61-65$ & 427011.8 & $15(20.3)$ & $442(12)$ & $<0.001$ \\
\hline 66 & $541(14.9)$ & $21(24.4)$ & $562(12.2)$ & $<0.001$ \\
\hline
\end{tabular}




\section{Source of Infection}

\begin{tabular}{|lllll|}
\hline Imported & $751(20.2)$ & $31(42)$ & $782(21.2)$ & 0.01 \\
\hline Local & $2870(79.3)$ & $43(58)$ & $2913(78.8)$ & $<0.001$ \\
\hline Clinical severity & & & & \\
\hline Mild & & & & \\
\hline Moderate & $2327(64.3)$ & $3(4.1)$ & $2330(36.1)$ & 0.01 \\
\hline Sever & $1101(30.4)$ & $7(9.5)$ & $1108(30)$ & 0.01 \\
\hline Critical & $102(2.8$ & $26(35.1)$ & $128(3.5)$ & $<0.001$ \\
\hline & $91(2.5)$ & $38(51.4)$ & $129(3.5)$ & $<0.001$ \\
\hline Geographic region & & & & \\
\hline & & & & \\
\hline Western Region & $1732(47.8)$ & $23(31.1)$ & $1755(47.5)$ & $<0.001$ \\
\hline Meddle region & $418(11.5)$ & $11(14.9)$ & $429(11.1)$ & 0.01 \\
\hline Southern Region & $1102(30.4)$ & $31(41.9)$ & $1133(30.7)$ & $<0.001$ \\
\hline Eastern Region & $729(20.1)$ & $9(12.2)$ & $738(20)$ & 0.01 \\
\hline
\end{tabular}

The age distribution of patients stratified by sex is shown in Fig 1. The median age of the infected cases was 55 years. $26.7 \%$ were aged sixty or above and only $86(2.4 \%)$ were children $<15$ years old. The incidence of infection rates increased progressively with age with males showing higher rates except for the latest (greater than 65 years of life) $(p=<0.001)$. This difference was also significant among patients above 50 years of age. The number of infected cases was a higher among males patients (68\%) indicating that men's cases of COVID-19 tended to be more serious than women's according to the clinical classification of severity.

The association between illness severity and age was shown in Fig. 2. It was shown that illness severity aggravated with age. The largest number Mild cases were reported among those aged below 45 years followed by moderate cases. moderate cases was higher among those aged below 45 years cases were mainly The large number of sever and critical cases were reported among older patients particularly after 60 years of age $(P<0.001)$ which accounted for $45(44.1 \%)$ and $51(56 \%)$ for mild and sever cases respectively. 
Figure 3 shows the overall temporal trend of weekly counts of newly confirmed COVID-19 cases by four Libyan Regions during the study period. COVID-19 pandemic had occurred sporadically until early May (first nine epi-weeks); 120 confirmed cases were reported mainly in Western region with 97 cases. The number of weekly confirmed COVID-19 cases subexponentially increased across the country from the 10th to 17th epi-week, followed by a slowly decrease over recent weeks. During the entire observation period, the highest number were reported within the Western (47.8\%), followed by Southern region $(30.4 \%)$ Meddle (30.4\%) and East regions (20.1\%) as shown in Fig 4.Howver, During epi-weeks 9-16, the proportion of confirmed cases decreased East and Meddle region, but highly increased in South Regions (Figure 4).

The dynamics of COVID-19 during the study period was shown in Fig 5. In the first eight epi-weeks the emergence of the pandemic was detected in five counties in Western region including, Tripoli which hosted the largest number of cases followed by , Zawia, Surman, Aljalaet and Nalut. Two counties in Meddle region, Musrata and Zleitan and only one county in Western region (Benghazi) and Southern region (Sebha) as illustrated in Fig. 5A.

The results from geographic clustering analysis are robust. Starting in the 9th epi-week, new clusters were emerged and came out largely from the Southern and West regions $(P=<0.001)$. In the following epiweeks pandemic spread all over the country and new cases were reported in each of the 22 counties as shown in Fig 5B. It is clearly evident that there is a positive correlation among the confirmed cases according to the geographical structure, and its spatial distribution has obvious agglomeration characteristics (Fig 5). The increase of confirmed cases in one city will inevitably lead to the increasing cases in adjacent cities, which means that a positive spillover effect occurs. The highest number were reported in Sebha (Southern region), Tripoli (Western region) and Musrta (Meddle region).

\section{Discussion}

The epidemiological and clinical details of COVID19 pandemic in Libya are well characterized in this study. Up to July $31^{\text {th }}$ a total of 3695 were reported which accounted of $6.2 / 10000$ of population. The mean age was 53 years old, with a male to female ratio of 2.1:1. Of these patients, $74(1.3 \%)$ were died. The largest number were reported in the Western and Southern regions which accounted for 1732 (47.8\%) and $418(11.5 \%)$ respectively. Though it was less in the Eastern $729(20.1 \%)$ and Meddle $418(11.5 \%)$ regions. Our data showed that COVID-19 infects men more than women; these findings are in concordance with other studies reported from China and Iran $[25,26]$. Although, there is no obvious reason for such gender variability speculation has been raised regarding the hormonal and genetic variation or even to social culture particularly in Middle-east and African countries. However, other studies have shown, similar susceptibility to SARS-CoV-2 between males and females [27].

Taking the patients' age into consideration, children ( $<15$ years) accounted only for 2.4 and those aged 20-50 years accounted for (4-9.5.\%) although those aged over 60 years represents the largest number of infected cases which accounted for 10-24\%. This is clearly evident that COVID-19 among Libyan correspondence to a higher age. In fact most deaths in infected individuals occurred in Italy, Spain and 
France occurred in old people suffering from severe conditions particularly in the early phases of the epidemics[28]. However, a recent study carried on the Libyan population demography shows that over 65 $\%$ of the Libyan population are aged less than 60 years old[29].

Based on our data the majority of the reported cases were mild 2327 (64.3\%)and moderate 1101 (30.4\%). Although only 102 (2.8\%) were Sever and 91 (2.5\%) Critical. The association between illness severity and age was evident in this study. It was shown that illness severity aggravated with age. Although the infected and deceased patients were significantly older than the patients who survived COVID-19, ages were comparable between males and females in both the deceased and the patients who survived. Furthermore, this study has showed that males tend to experience more serious cases of COVID-19 than females according to the clinical classification of severity including Mild, Moderate, Severe, and Critical. This is in agreement with other studies carried by Li etal, and Jian-Min etal. who showed that men's cases tended to be more serious than women's[19,30]. Therefore, gender may be considered as a risk factor for higher severity and mortality in patients with COVID-19, independent of age and susceptibility.

In this study we evaluated the spatial and temporal patterns of the COVID-19 pandemic in Libya within the first 16 Epi-weeks of the epidemic. In the early stage of the COVID-19 outbreak, few sporadic cases were reported in first six Epi-weeks in Tripoli at the Western region. By the end of the $8^{\text {th }}$ epi-week, the cases spread to cities neighboring Tripoli such as Musrta and Zawia ; the first-order neighboring cities showed a particularly increased number of confirmed cases. Since then, the number of weekly confirmed COVID-19 cases exponentially increased across the country from the 9 th to 16 th epi-week. During the entire, study period, the prevalence of COVID-19 in Libyan regions showed striking variations. The epidemic was much higher and important in Western and Southern regions though it was less in Meddle and Eastern regions. This is more likely to depend on the different timing of the onset of the outbreak in each regions [31,32].

it is clearly evident in this study that the dynamics of the epidemic in Libya followed a geographical differentiation, with a strong West to South gradient, although no region was free of cases and deaths at the end of August. In all regions, both morbidity and mortality curves tended to depart from linear lines up and no sign of flattening with time, thus highlighting critical situation of the epidemic. Similar trends were observed early stages of spread COVID-19 in Italy. Spain and France. Hence then specific strategies should be implemented to contain the soared of the pandemic $[33,34]$.

Despite that the study gave a detailed information regarding the Epidemiology of COVID-19 in Libya. The reported data suffer from many uncertainties and limitations. These may include. First, the confirmed cases of COVID-19 might not reflect the actual number of persons infected by COVID-19 as many cases were a symptomatic and some went untested further to the limited testing resources in the country. Second the study did not highlights the impact of the ongoing armed conflict on spread of COVID-19 in Libya which defiantly hinder the accurate number of cases in certain cities. Third, the study, did not cover certain groups such as immigrants displaced population and injured people who are prone at higher risk of COVID-19 [35-37]. 


\section{Conclusion}

This study is the first to provide information on epidemiological characterization and the spatial and temporal patterns of the COVID-19 pandemic in Libya. It is conclusively evident that the pandemic has affected the whole country, with incidence rates varying from region to another. Meanwhile, the prevention and control of COVID-19 in Libya is still a severe fight. We have seen the health system of the some European countries buckled under the surge of COVID-19 and appealed for help[38,39]. The internal conflict in Libya has affected the national health care system immensely. There is a dearth of information on the capacity to provide care for critically ill patients in ICUs in Libya in addition to lack of accuracy and efficient tracing policy of COVID-19 infected cases. Hence then, Swift action to control further spread of the virus, and to improve the response capabilities is urgently needed[40,41]. The study demonstrated the spatiotemporal characteristics and trends of COVID-19 in Libya which is essential to better focus on preventive efforts. The country must scale up its containment and mitigation strategies - quarantine, isolation, and social distancing. Establishing a functional infection prevention and control practices that could help to detect and to contain the ongoing epidemic[42,43]

\section{Declarations}

\section{Acknowledgements}

We are deeply grateful to the Libyan Study Group of Hepatitis \& HIV, the

Department of Medical Microbiology, Faculty of Medicine for their help and support.

\section{Ethical approval and consent to participate}

The Medical Ethics Committee at the Faculty of Medicine, University of Tripoli approved the study and waived the need for approval by the Libyan National Ethics Committee. As the study was an analysis of epidemiological data obtained at a national population level, it needed no consent from the participants.

\section{Funding}

No funding was received for this study.

\section{Availability of data and materials}

The data presented in this paper are freely available upon request.

\section{Authors' contributions}


MD conceived and designed the study. MD and AE contributed to the analysis tools,. MD designed the analysis, analyzed the data, and performed cartography. MD wrote the paper. AE and MA; made substantial contributions to conception and design, or acquisition of data, or analysis and interpretation of data MD, MA, and AE provided advice and critically reviewed the manuscript. All authors read and approved the final manuscript.

\section{Consent for publication}

Not applicable.

\section{Competing interests}

The authors declare that they have no competing interests.

Publisher's Note

Springer Nature remains neutral with regard to jurisdictional claims in published maps and institutional affiliations.

\section{Author details}

Department of Medical Microbiology \&lmmunology, Faculty of Medicine,

University of Tripoli, CC 82668 Tripoli, Libya.

Department of Laboratory Medicine, Faculty of Biotechnology, University of Tripoli , CC 82668 Tripoli, Libya.

Department of Microbiology \& Parasitology, Faculty of Veterinary Medicine, University of Tripoli, CC 82668Libya.

\section{References}

1. Haffajee RL, Mello MM. Thinking globally, acting locally-The US response to COVID-19. New England Journal of Medicine. 2020 May 28;382(22):e75.

2. Gianicolo E, Riccetti N, Blettner M, Karch A. Epidemiological Measures in the Context of the COVID-19 Pandemic. Deutsches Ärzteblatt International. 2020 May;117(19):336.

3. Spiteri G, Fielding J, Diercke M, Campese C, Enouf V, Gaymard A, Bella A, Sognamiglio P, Moros MJ, Riutort AN, Demina YV. First cases of coronavirus disease 2019 (COVID-19) in the WHO European Region, 24 January to 21 February 2020. Eurosurveillance. 2020 Mar 5;25(9):2000178. 
4. Mohanty SK, Dubey M, Mishra US, Sahoo U. Impact of COVID-19 Attributable Deaths on Longevity, Premature Mortality and DALY: Estimates of USA, Italy, Sweden and Germany. medRxiv. 2020 Jan 1.

5. Pourghasemi HR, Pouyan S, Heidari B, Farajzadeh Z, Shamsi SR, Babaei S, Khosravi R, Etemadi M, Ghanbarian G, Farhadi A, Safaeian R. Spatial modelling, risk mapping, change detection, and outbreak trend analysis of coronavirus (COVID-19) in Iran (days between 19 February to 14 June 2020). International Journal of Infectious Diseases. 2020 Jun 20.

6. de Souza WM, Buss LF, da Silva Candido D, Carrera JP, Li S, Zarebski A, Vincenti-Gonzalez M, Messina J, da Silva Sales FC, dos Santos Andrade P, Prete CA. Epidemiological and clinical characteristics of the early phase of the COVID-19 epidemic in Brazil. medRxiv. 2020 Jan 1.

7. Gilbert M, Pullano G, Pinotti F, Valdano E, Poletto C, Boëlle PY, d'Ortenzio E, Yazdanpanah Y, Eholie SP, Altmann M, Gutierrez B. Preparedness and vulnerability of African countries against importations of COVID-19: a modelling study. The Lancet. 2020 Mar 14;395(10227):871-7.

8. Da'ar OB, Haji M, Jradi H. Coronavirus Disease 2019 (COVID-19): Potential implications for weak health systems and conflict zones in the Middle East and North Africa region. The International journal of health planning and management. 2020 Jun 19.

9. Gyasi RM. Fighting COVID-19: Fear and internal conflict among older adults in Ghana. Journal of gerontological social work. 2020 Jun 20:1-3

10. Daw MA, El-Bouzedi AH, Ahmed MO, Cheikh Y. Spatial Distribution and Geographic Mapping of COVID-19 in Northern African Countries; A Preliminary Study. J Clin Immunol Immunother. 2020;6:032.

11. Arashi M, Bekker A, Salehi M, Millard S, Erasmus B, Cronje T, Golpaygani M. Spatial analysis and prediction of COVID-19 spread in South Africa after lockdown. arXiv preprint arXiv:2005.09596. 2020 May 19.

12. Daw MA. Libyan healthcare system during the armed conflict: Challenges and restoration. African Journal of Emergency Medicine. 2017 Jun;7(2):47.

13. Daw MA, El-Bouzedi A, Dau AA. The assessment of efficiency and coordination within the Libyan health care system during the armed conflict-2011. Clinical Epidemiology and Global Health. 2016 Sep 1;4(3):120-7.

14. Daw MA. Preliminary epidemiological analysis of suspected cases of corona virus infection in Libya. Travel medicine and infectious disease. 2020 Mar 20.

15. Daw MA. Corona virus infection in Syria, Libya and Yemen; an alarming devastating threat. Trav Med Infect Dis. 2020 Apr 2;101652.

16. Daw MA, El-Bouzedi A, Dau AA. Libyan armed conflict 2011: mortality, injury and population displacement. African Journal of Emergency Medicine. 2015 Sep 1;5(3):101-7.

17. Rajendran DK, Rajagopal V, Alagumanian S, Kumar TS, Prabhakaran SS, Kasilingam D. Systematic literature review on novel corona virus SARS-CoV-2: a threat to human era. VirusDisease. 2020 Jun 11:1-3. 
18. Daw MA, El-Bouzedi AH. Modelling the epidemic spread of COVID-19 virus infection in Northern African countries. Travel Medicine and Infectious Disease. 2020 Apr 15.

19. Jin JM, Bai P, He W, Wu F, Liu XF, Han DM, Liu S, Yang JK. Gender differences in patients with COVID19: Focus on severity and mortality. Frontiers in Public Health. 2020 Apr 29;8:152.

20. Organization WH. Laboratory testing for coronavirus disease 2019 (COVID-19) in suspected human cases: interim guidance. Geneva: World Health Available:

https://apps.who.int/iris/bitstream/handle/1 0665/331329/WHO-COVID-19-laboratory-2020.4eng.pdf. Accessed 2 Mar 2020.

21. Organization $\mathrm{WH}$. Clinical management of severe acute respiratory infection when novel coronavirus (nCoV) infection is suspected: interim guidance, 25 January 2020. Geneva: World Health Organization; 2020 2020. Contract No.:WHO/nCoV/Clinical/

22. Daw MA, Daw AM, Sifennasr NE, Draha AM, Daw AA, Daw AA, Ahmed MO, Mokhtar ES, El-Bouzedi AH, Daw IM, Adam SI. Spatiotemporal analysis and epidemiological characterization of the human immunodeficiency virus (HIV) in Libya within a twenty five year period: 1993-2017. AIDS research and therapy. $2019 \mathrm{Dec} ; 16(1): 1-9$.

23. Daw MA, Daw AM, Sifennasr NE, Draha A, Daw A, Daw A, Ahmed M, Mokhtar E, El-Bouzedi A, Daw I, Adam S. The epidemiological characterization and geographic distribution of Hepatitis $D$ virus infection in Libya. The Pan African Medical Journal. 2020 Apr 14;35(120).

24. (24)-Daw MA, Ali LA, Daw AM, Sifennasr NE, Dau AA, Agnan MM, El-Bouzedi A. The geographic variation and spatiotemporal distribution of hepatitis $C$ virus infection in Libya: 2007-2016. BMC infectious diseases. 2018 Dec 1;18(1):594.

25. Yang Y, Lu Q, Liu M, Wang Y, Zhang A, Jalali N, Dean N, Longini I, Halloran ME, Xu B, Zhang X. Epidemiological and clinical features of the 2019 novel coronavirus outbreak in China. MedRxiv. 2020 Jan 1.

26. Shahriarirad R, Khodamoradi Z, Erfani A, Hosseinpour H, Ranjbar K, Emami Y, Mirahmadizadeh A, Lotfi M, Yeganeh BS, Nejad AD, Hemmati A. Epidemiological and clinical features of 2019 novel coronavirus diseases (COVID-19) in the South of Iran. BMC infectious diseases. 2020 Dec;20(1):1-2.

27. Klein SL, Dhakal S, Ursin RL, Deshpande S, Sandberg K, Mauvais-Jarvis F. Biological sex impacts COVID-19 outcomes. PLoS pathogens. 2020 Jun 22;16(6):e1008570.

28. Ceylan Z. Estimation of COVID-19 prevalence in Italy, Spain, and France. Science of The Total Environment. 2020 Apr 22:138817.

29. Daw MA, El-Bouzedi AH. Trends and projection of demographic indices of the Libyan population using a fifty-year census data 1954-2016. African Population Studies. 2019 Aug 6;33(2).

30. Li Q, Guan X, Wu P, Wang X, Zhou L, Tong Y, et al. Early Transmission dynamics in Wuhan, China, of novel coronavirus-infected pneumonia. N Engl J Med. (2020) 382:1199-207. doi: 10.1056/NEJMoa 2001316

31. Sun F, Matthews SA, Yang TC, Hu MH. A spatial analysis of COVID-19 period prevalence in US counties through June 28, 2020: Where geography matters?. Annals of Epidemiology. 2020 Jul 28. 
32. Rose-Redwood R, Kitchin R, Apostolopoulou E, Rickards L, Blackman T, Crampton J, Rossi U, Buckley M. Geographies of the COVID-19 pandemic. Dialogues in Human Geography. $2020 \mathrm{Jul}$ 1:2043820620936050.

33. La Maestra S, Abbondandolo A, De Flora S. Epidemiological trends of COVID-19 epidemic in Italy over March 2020: From 1000 to 100000 cases. Journal of medical virology. 2020 Apr 21.

34. Mavragani A. Tracking COVID-19 in Europe: an infodemiology study. JMIR Public Health and Surveillance. 2020;6(2).

35. Daw MA, El-Bouzedi A, Ahmed MO, Dau AA, Agnan MM. Epidemiology of hepatitis $C$ virus and genotype distribution in immigrants crossing to Europe from North and sub-Saharan Africa. Travel Medicine and Infectious Disease. 2016 Sep 1;14(5):517-26.

36. Daw MA, El-Bouzedi A, Ahmed MO, Dau AA, Agnan MM, Drah AM, Deake AO. Prevalence of human immune deficiency virus in immigrants crossing to Europe from North and Sub-Saharan Africa. Travel Med Infect Dis. 2016 Nov 1;14(6):637-8.

37. Daw MA, Sifennasr NE, El-Bouzedi A, Daeke AO, Dau AA, Drah AM, Ahmed MO, Agnan MM. Epidemiology of hepatitis B virus in immigrants crossing to Europe from North and Sub-Saharan Africa. Travel medicine and infectious disease. 2017;16:59.

38. Eurosurveillance Editorial Team. Updated rapid risk assessment from ECDC on the novel coronavirus disease 2019 (COVID-19) pandemic: increased transmission in the EU/EEA and the UK. Eurosurveillance. 2020 Mar 12;25(10).

39. Hirota K. Air contamination with SARS-CoV-2 in the operating room. Journal of anesthesia. 2020 Jun 19:1-4.

40. Bedford J, Enria D, Giesecke J, Heymann DL, Ihekweazu C, Kobinger G, Lane HC, Memish Z, Oh MD, Schuchat A, Ungchusak K. COVID-19: towards controlling of a pandemic. The Lancet. 2020 Mar 28;395(10229):1015-8

41. Tanne JH, Hayasaki E, Zastrow M, Pulla P, Smith P, Rada AG. Covid-19: how doctors and healthcare systems are tackling coronavirus worldwide. Bmj. 2020 Mar 18;368.

42. Zhang $Q$, Deng $H$, Zhang $C$. The value of early response by surrounding areas of epidemic center Hubei during COVID-2019 outbreak in China: A quasi-experiment analysis. Available at SSRN 3548372. 2020 Mar 4.

43. Saglietto A, D'Ascenzo F, Zoccai GB, De Ferrari GM. COVID-19 in Europe: the Italian lesson. Lancet. 2020 Apr 4;395(10230):1110-.

\section{Figures}




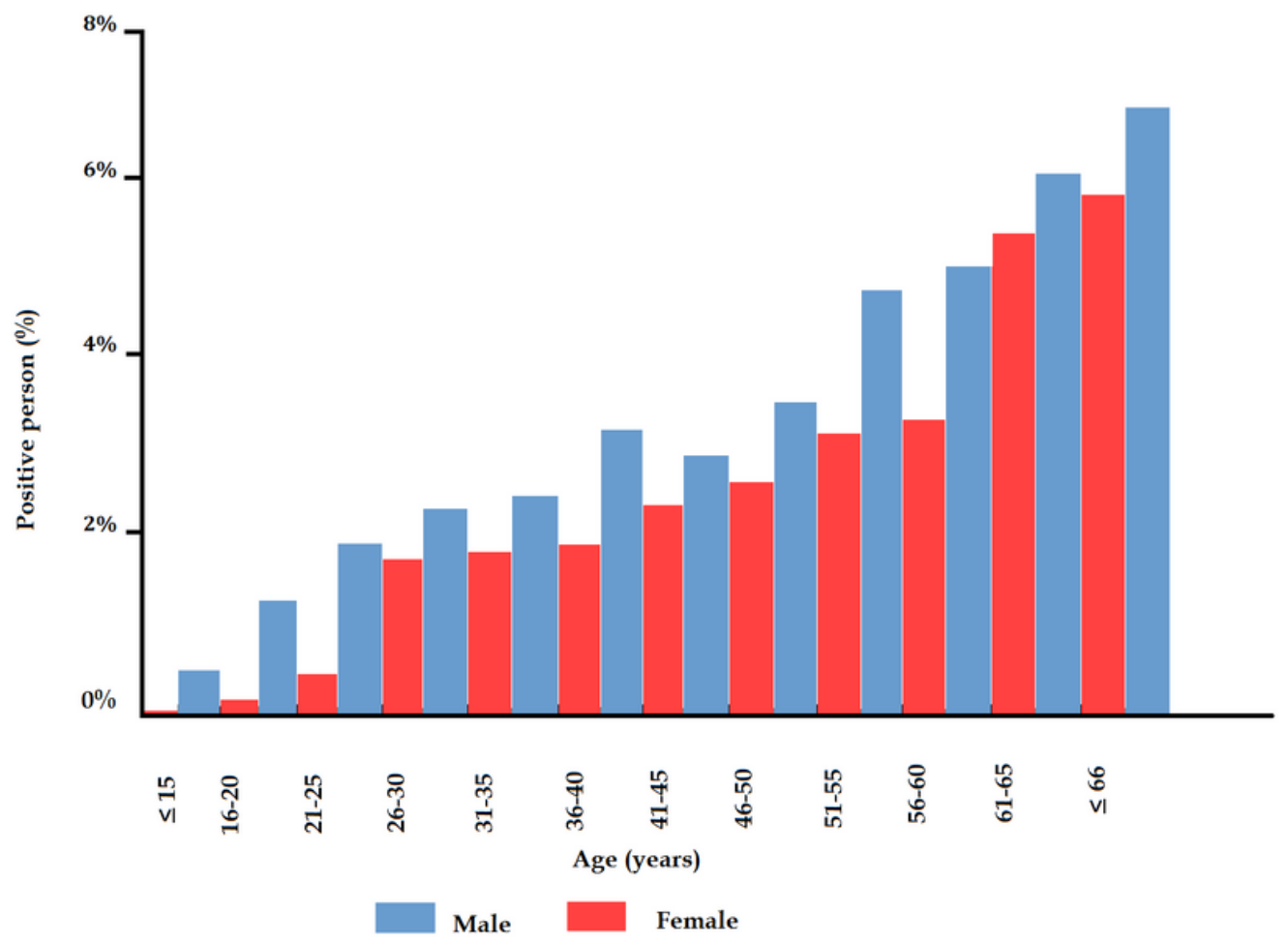

Figure 1

The age and gender distribution of confirmed cases of CIVID-19 infection during the study period. Males (blue bars) and females (red bars) 


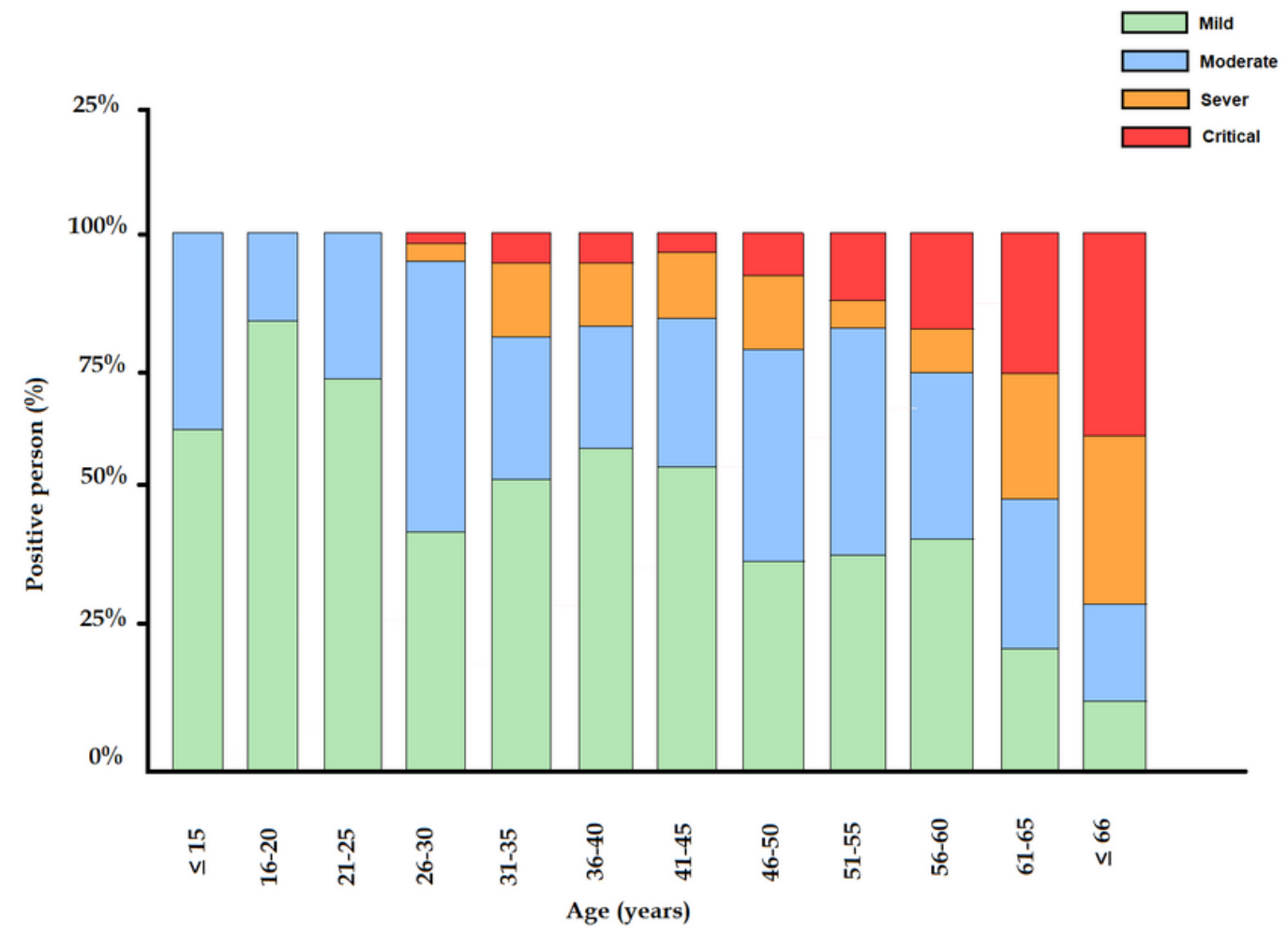

Figure 2

The clinical severity of confirmed cases with COVID-19 infection. The different version of definition for confirmed cases were marked, Mild, Moderate, Sever, Critical 


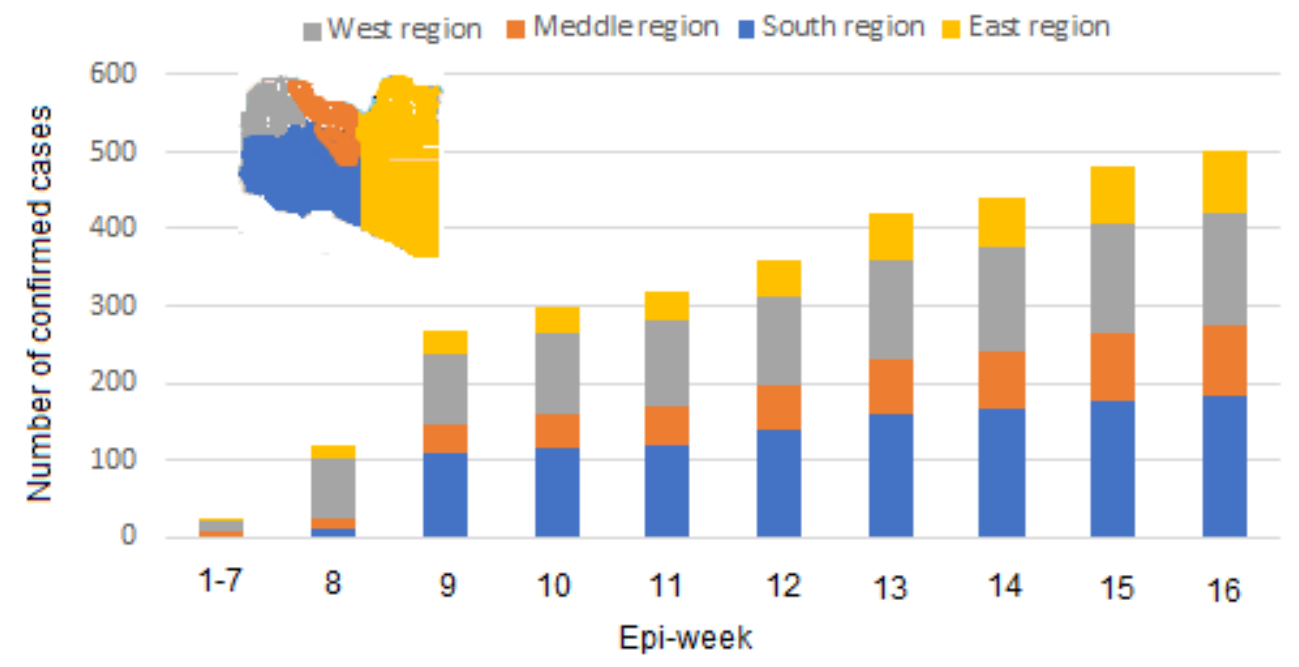

Figure 3

The weekly incidence trends of confirmed cases of COVID-19 in each Libyan region during the study period.

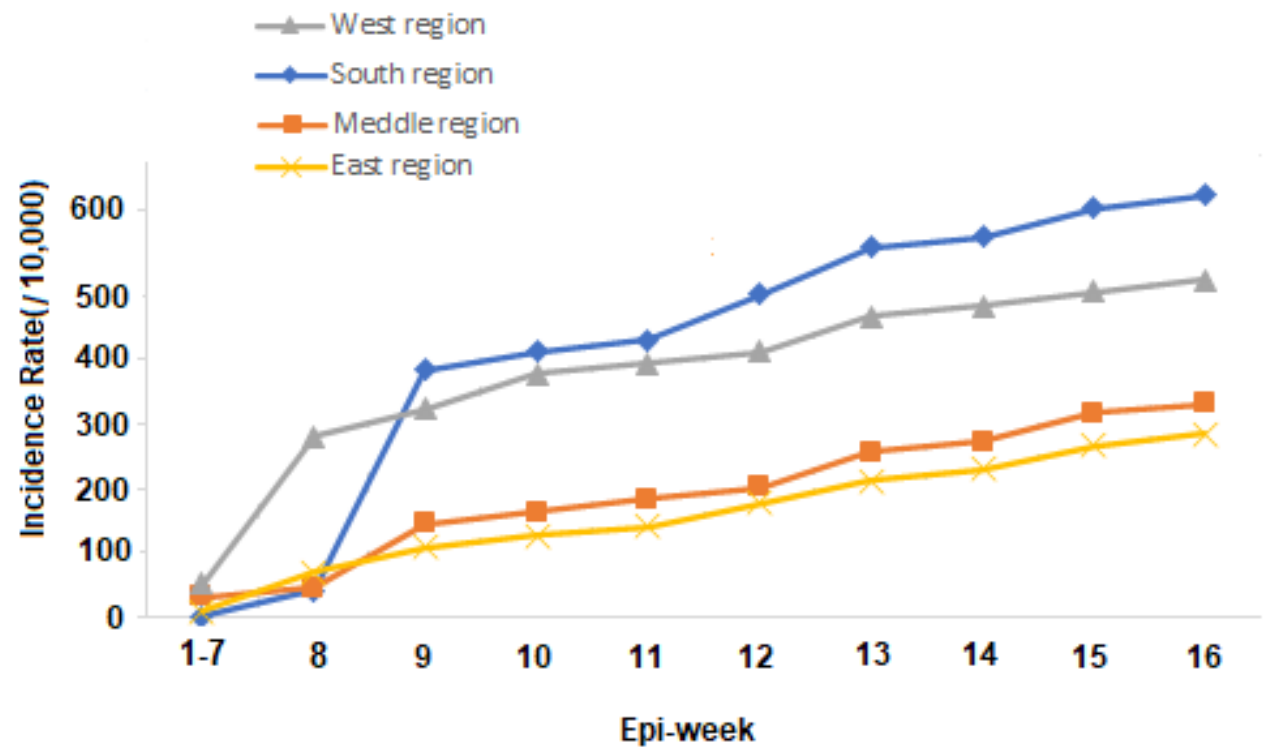

Figure 4

The prevalence of COVID-19 cases among the Libyan population across the four geographic regions over 16 epi-weeks, April 03-August 31, 2020. 


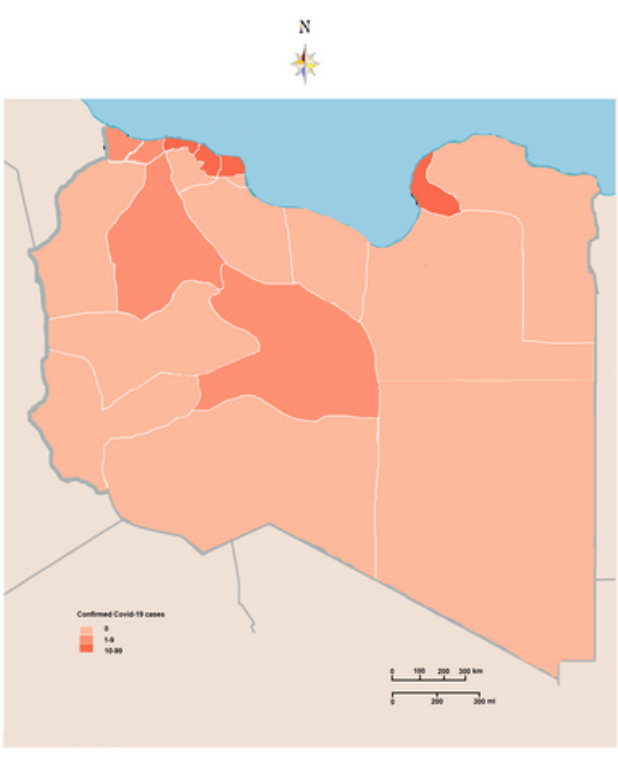

A : Epi-weeks, 1-8

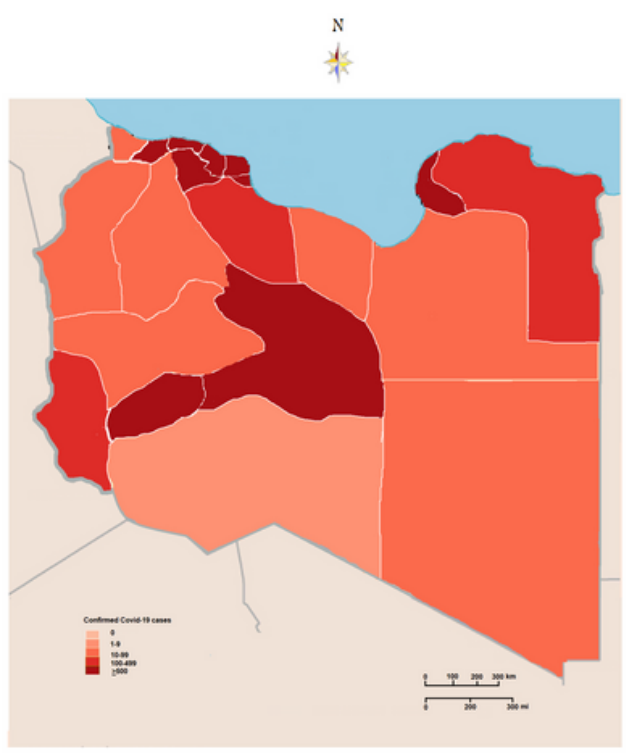

B : Epi-weeks, 9-16

\section{Figure 5}

Geograpic and sptiotemporal distribution of the confirmed cases of COVID-19 in Libya A-during the early stage of the epidemic ( 1-8) epi-weeks B-During the second stage of the epidemioc ( 9-16) epi-weeks 